\title{
In with the New
}

\section{from the eniltors}

\section{Charlene O'Hanlon, ACM Queue}

A h, December. That time of year when endings and beginnings are as prevalent as Salvation Army Santas. Amid the holiday parties, shopping for presents, and drinking and eating too much of the stuff that's really bad for us, most of us take some time to reflect on the year that is now behind us and contemplate ways to make the new year better than the last.

We're no different here at ACM Queue. Yes, we like to eat (and occasionally drink) too much of the stuff that's bad for us, and we, too, have taken some time to reflect on the ways we can make 2006 a better year for Queue and for you, our readers. Being in the business of communication, we decided that would be a good place to start.

Starting next month, ACM Queue will join the bloggerati ranks as we host a community blog on our Web site. The community-ACM Queue's editorial staff, Editorial Advisory Board members, and the occasional guest expert-will share their thoughts on all things related to Queue, its content, and its readership. We expect it to lead to some interesting discourse, and hope it will help you better understand the collective brain trust that steers the editorial direction of Queue each month. If nothing else, I hope the blog inspires discussion about those issues we aren't covering and helps us create relevant content.

Also starting next month-and I, for one, am awfully excited about this-ACM Queue will host monthly podcasts on our site. ACM Queuecasts: Discussions with the Experts will be a series of conversations with technologists and other industry leaders, and will focus on a particular topic relevant to the corresponding print issue for that month. Look for January's Queuecast to be on the subject of this month's issue, Managing Megaservices.

ACM Queuecasts will be made available on the ACM Queue Web site via a downloadable file users can listen to on their computers or put on their MP3 players. The discussions will be led by Michael Vizard, a technology journalist and editor and cohost of a technology-focused daily radio show on the Sirius satellite radio network.

Listeners of ACM Queuecasts will be able to post their comments to the Queuecast section of ACM Queue's Web site, and those comments will be readily available as a thread on the site for others to read and respond to. ACM

What's ahead
FOR QUEUE
IN 2006?

ing online chats. The Queuecasts will be archived in and accessible from ACM's Digital Library.

The addition of the blog and ACM Queuecasts will facilitate changes to ACM Queue's Web site. Starting in 2006, we're redesigning www.acmqueue.com to be more readable and look less cluttered. Some changes will be obvious, others more subtle, but the goal is to present the content in a more sensible way to make your visit to the site a better, more positive experience. Any comments you have regarding ways we can make acmqueue.com a better site will help us tremendously in this endeavor.

We're working on ways to make ACM Queue a better publication behind the scenes, as well. Among other endeavors, we have instituted a monthly reader satisfaction survey to gauge how well we are hitting the mark each month, both with our on-theme articles and our monthly columns. The nine-question surveys are sent via e-mail to a random sample of readers each month, so if you see an e-mail from ACM Queue with the subject line, "ACM Queue-How Is Your Reading Experience?" please read it and fill out the questionnaire! Your comments will make all the difference.

The digital version of ACM Queue is also now up and running for those who don't like to lug around a paper copy of the magazine. Want to switch your subscription to receive an electronic version of ACM Queue each month? Just send a message to our subscription department at queuemagazine@acm.org and they'll be happy to convert it for you.

As always, the lines of communication to me are also open. Please send me your thoughts, ideas, questions, comments, kudos, criticisms, and jokes. And may you have a happy, healthy, and safe holiday. Cheers! Q

CHARLENE O'HANLON, ACM Queue's editor and publisher, thinks the best gift this holiday season would be a whole week of uninterrupted sleep. 